\title{
Drought resistance of Astragalus cicer and $A$. sulcatus at the initial stages of plants development
}

\author{
Tatyana Kornievskaya ${ }^{1, *}$ \\ ${ }^{1}$ Altai State University 656049, Barnaul, Lenina Str., 61, Russia
}

\begin{abstract}
The article considers laboratory evaluation methods of water stress influence on the initial stages of Astragalus cicer and A. sulcatus development by seeds ability to germinate in osmotic sucrose solutions, characteristics of radicles and depression of shoots growth processes induced by the solution osmotic pressure. Osmoregulatory characteristics of seeds are estimated. It was ascertained that the rise in solution osmotic pressure up to $2 \mathrm{~atm}$ leads to a twofold and fivefold decrease in seeds germinating capacity in A. cicer and A. sulcatus respectively. At the sucrose concentration level of $4 \mathrm{~atm}$, seeds do not germinate at all. Strong concentrations of osmotic solutions cause the depression of shoots growth processes and the reduction of astragaluses dry biomass.
\end{abstract}

\section{Introduction}

Territories belonging to various soil-geographical regions of our planet are constantly or periodically exposed to drought, which leads to significant crop losses. The total area of the arid territories having less than $250 \mathrm{~mm}$ annual precipitation constitutes more than a third of the earth's surface. First of all, drought deteriorates the seeds germination and the young crops condition, as long as the initial stages of plants development are the most vulnerable. Young shoots lose the tie with the seed and become completely dependent on the external factors, i.e. mineral and water supply, air and soil humidity. Drought causes stomata of plants to close, which in its turn leads to the decline in the photosynthetic efficiency, productivity and crops quality [1].

The reaction of different plant species to the lack of water depends on the level of their sustainability, which quantitative measure is the degree of productivity decrease in response to the stress pressure [2]. Drought resistance is an important ecological adaptation determining the combination of genes that influence biochemical, physiological and morphological characteristics of the individual.

Drought resistance evaluation of the plant species and cultivars with the application of indirect laboratory methods is becoming the most popular nowadays.

Laboratory methods allow detecting the seeds and shoots condition by means of their cultivation in osmotic sucrose solutions imitating water deficiency. These methods allow us

\footnotetext{
* Corresponding author: galtsovatw@yandex.ru
} 
to estimate the plants ability to withstand the lack of moisture at the early stages of ontogeny within a short period regardless of the weather conditions. S. Grzesiak [3] consider that laboratory methods of plants drought resistance evaluation with the use of osmotic solutions (sucrose, mannitol, etc.) are an adequate criterion to determine plants sustainability to water deficiency and are comparable to direct methods.

Several scientists [4] noted the dependence of plants drought resistance on the complex of morphological and physiological parameters. The rate of root system growth and vigor as special means of obtaining water and mineral substances are regarded as the most significant traits.

A. Bukhinger was the first to suggest the idea to evaluate the drought resistance of plants by the suction force that germinating seeds develop in the sucrose solution. The higher the root system growth rate and the greater the rooting depth are, the more the drought resistance is [5].

\section{Materials and methods}

The material of the study was the seeds of two astragalus species being introduced in the dry steppe conditions of Mikhaylovskiy region (Altai krai) - Astragalus cicer L. and A. sulcatus L. gathered in 2017. The evaluation of water stress influence on the growth and development of astragaluses was carried out by means of three indirect methods: seeds ability to germinate in osmotic sucrose solutions, characteristics of radicles and depression of shoots growth processes caused by the osmotic pressure of the solution [6].

For the purpose of the evaluation of astragalus drought resistance, diluted concentrations of sucrose solutions with the osmotic pressure of 2 and 4 atmospheres were selected. The sucrose mass fraction in the solution was determined with the use of the van't Hoff equation in accordance with the target osmotic pressure by the formula:

$$
P_{o s m}=C_{M} \times R \times T(P a)
$$

$\mathrm{P}_{\mathrm{osm}}$ - osmotic pressure $(\mathrm{Pa})$;

$\mathrm{C}_{\mathrm{M}}$ - sucrose molality ( $\left.\mathrm{mol} / \mathrm{L}\right)$;

$\mathrm{R}-$ gas constant $(\mathrm{J} / \mathrm{mol} \times \mathrm{K})$;

$\mathrm{T}$ - temperature (Kelvin), at $+20^{\circ} \mathrm{C}$.

The viability of seeds was estimated by the Yu.D. Akhlamova procedure [7].

The seeds, preliminarily scarified by concentrated sulphuric acid, were placed on filter paper in Petrie dishes (50 seeds per dish) with four-fold replication (for the osmotic sucrose solutions) and two-fold replication for the reference sample (distilled water). The seeds were poured over up to maximum water holding capacity with $5 \mathrm{ml}$ of the sucrose solution with the respective osmotic pressure (experiment) or water (reference).

The seed sprouting was carried out at room temperature of $+19-20^{\circ} \mathrm{C}$. Germinative capacity was determined on the seventh day.

In order to predict the drought resistance of plants in early ontogeny in the conditions of insufficient moisture supply, we studied the peculiarities of the root biomass formation. On the seventh day, we counted the number of the radicles (pcs), measured the radicles mass (mg) and their length ( $\mathrm{mm})$. Different characteristics of the radicles in the sucrose solutions were compared to the reference sample (water).

After determination of the seed germinative capacity, the radicles and shoots in each Petrie dish were cut down, put into weighing bottles, placed into an oven and dried for 3 hours at the temperature of $+105^{\circ} \mathrm{C}$. After drying, the material was cooled in the desiccator and weighed on the analytical balance. The average dry mass of the sprouts per one 
replication in the reference sample was set at $100 \%(\mathrm{x})$, while the average dry mass in the experiment (y) was determined as percentage of the dry mass in the reference sample.

The depression degree $(Z)$ in the accumulation of dry mass by the shoots at high osmotic pressure was calculated by the formula:

$$
Z=100-y / x \times 100
$$

On the basis of three considered methods, we differentiated between four groups of shoots resistance: I - drought resistant (80-100\%), II - resistant (60-79\%), III - low resistant (40-59\%), IV - non-resistant (0-39\%).

\section{Results of the research}

Based on the laboratory germinative capacity of the astragalus seeds in concentrated sucrose solutions, we noticed a tendency towards its decrease if the concentration of the solution increases. The seeds of Astragalus cicer and A. sulcatus in the reference sample were characterized by high percentage of germinative capacity: $88 \%$ and $76 \%$ respectively. Increase in the concentration of the solution up to $2 \mathrm{~atm}$ leads to a significant decline in germinative capacity of Astragalus cicer (two times less $-42 \%$ ) and to a five-time fall in germinative capacity of Astragalus sulcatus (15\%) (Table 1). At the sucrose concentration level of $4 \mathrm{~atm}$, seeds do not germinate at all. This indicates the low sustainability of seeds and shoots to water deficiency.

Table 1. Influence of the osmotic pressure on the formation of radicles and aboveground sprout shoots of Astragalus species.

\begin{tabular}{|c|c|c|c|c|c|c|c|c|c|c|}
\hline \multirow[b]{2}{*}{ 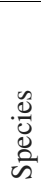 } & \multirow[t]{2}{*}{$\begin{array}{l}\mathrm{V}, \\
\%\end{array}$} & \multicolumn{3}{|c|}{$\begin{array}{c}\text { Germinative capacity, } \\
\%\end{array}$} & \multicolumn{3}{|c|}{ Roots length, mm } & \multicolumn{3}{|c|}{ Sprouts length, mm } \\
\hline & & $\mathrm{RS}$ & $\begin{array}{c}\mathrm{P}_{\mathrm{osm}}=2 \\
\mathrm{~atm}\end{array}$ & $\begin{array}{c}\mathrm{P}_{\mathrm{osm}}=4 \\
\text { atm. }\end{array}$ & $\begin{array}{c}\mathrm{RS} \\
\mathrm{X} \pm \mathrm{m}\end{array}$ & $\begin{array}{c}\mathrm{P}_{\mathrm{osm}}=2 \\
\mathrm{~atm} \\
\mathrm{X} \pm \mathrm{m}\end{array}$ & $\begin{array}{c}P_{\text {osm }} \\
=4 \\
\text { atm. }\end{array}$ & $\begin{array}{c}\text { RS } \\
X \pm m\end{array}$ & $\begin{array}{c}\mathrm{P}_{\mathrm{osm}}=2 \\
\text { atm. } \\
\mathrm{X} \pm \mathrm{m}\end{array}$ & $\begin{array}{l}P_{\text {osm }} \\
=4 \\
\text { atm. }\end{array}$ \\
\hline 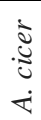 & 97 & 88 & 42 & 0,25 & $7,6 \pm 0,38$ & $4,5 \pm 0,33$ & 2,0 & $10,5 \pm 0,42$ & $5,97 \pm 0,22$ & 4,0 \\
\hline 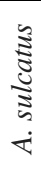 & 96 & 76 & 15 & 0,50 & $4,0 \pm 0,45$ & $2,2 \pm 0,18$ & 1,0 & $7,8 \pm 0,34$ & $4,6 \pm 0,39$ & 2,0 \\
\hline
\end{tabular}

Note to Figure 1: V - viability, RS - reference sample (distilled water), $\mathrm{P}_{\mathrm{osm}}$ - osmotic pressure of the sucrose solution.

Water stress causes the growth inhibition of the aboveground and underground plant organs, which is reflected in the overall condition of the shoots. The examined astragaluses samples were characterized by the depression of growth processes in the solutions with elevated concentration of sucrose. We observed a twofold decrease in size and biomass of shoots and radicles in comparison with the reference sample if the osmotic pressure was strong (Table 1,2). 
Table 2. Influence of water stress caused by high osmotic pressure of the sucrose solution on the growth processes depression in astragaluses.

\begin{tabular}{|c|c|c|c|c|c|c|c|c|}
\hline \multirow[t]{3}{*}{ Species } & \multicolumn{3}{|c|}{ Absolute dry roots biomass, $\mathrm{mg}$} & \multicolumn{3}{|c|}{ Absolute dry sprouts biomass, $\mathrm{mg}$} & \multicolumn{2}{|c|}{$\begin{array}{l}\text { Degree of growth } \\
\text { processes depression } \\
\text { (Z), } \%\end{array}$} \\
\hline & \multirow{2}{*}{$\begin{array}{l}\text { Reference } \\
\text { sample }\end{array}$} & \multirow{2}{*}{$\begin{array}{c}\mathrm{P}_{\mathrm{osm}}=2 \\
\text { atm. }\end{array}$} & \multirow{2}{*}{$\begin{array}{c}\mathrm{P}_{\mathrm{osm}}=4 \\
\text { atm. }\end{array}$} & \multirow{2}{*}{$\begin{array}{c}\text { Reference } \\
\text { sample }\end{array}$} & \multirow{2}{*}{$\begin{array}{c}\mathrm{P}_{\mathrm{osm}}=2 \\
\text { atm. }\end{array}$} & \multirow{2}{*}{$\begin{array}{c}\mathrm{P}_{\mathrm{osm}}=4 \\
\mathrm{~atm} .\end{array}$} & & \\
\hline & & & & & & & roots & sprouts \\
\hline A. cicer & 14,25 & 1,17 & - & 117,00 & 43,90 & - & 91,79 & 62,48 \\
\hline $\begin{array}{l}\text { A. } \\
\text { sulcatus }\end{array}$ & 53,43 & 1,40 & - & 30,41 & 6,50 & - & 97,38 & 78,63 \\
\hline
\end{tabular}

The determination of the drought resistance by the depression of the growth processes in plants at the initial stages of ontogeny depends on the rate of the dry mass accumulation by shoots in the conditions of insufficient water supply. Imitated drought influenced the accumulation of biomass in both aboveground and underground parts of the shoots. In case of water deficiency, the root system of astragaluses demonstrated the highest degree of growth processes depression $(91,79 \%$ - A. cicer, $97,38 \%$ - A. sulcatus $)$, which speaks in favor of a greater degree of the growth processes inhibition in roots as compared to the aboveground vegetative plant parts. A high depression level in shoots is indicative of astragaluses susceptibility to water deficiency.

\section{Conclusions}

We determined the astragaluses seeds ability to germinate in osmotic sucrose solutions. The osmotic pressure of $4 \mathrm{~atm}$ leads to a complete suppression of the growth processes and inability of the seeds to germinate, which indicates low osmoregulatory characteristics of the latter.

The size and biomass of the shoots are significantly smaller in the conditions of water deficiency. Depression of the growth processes in radicles demonstrated a low water potential of the shoots in case of elevated concentration of water solution. The astragalus shoots have low suction force, which manifests their low drought resistance.

The considered complex of laboratory methods evaluating the astragaluses drought resistance at the initial stages of ontogeny allows us to refer A. cicer and A. sulcatus to the group of non-resistant species.

\section{References}

1. S.A. Anjum, X. Xie, L. Wang, M.F. Saleem, C. Man, Afr. J. of Agric. R. 6, 2026$2032(2011)$

2. G.V. Udovenko, Proceed. on appl. bot., gen. and breed 64, 5-22 (1979) (in Russian)

3. S. Grzesiak, G. Skrudlik, W. Filek, B. Niziol, J. Agr. C. Scien. 177, 245-252 (2008)

4. G.G. Borisova, M.G. Maleva, N.V. Chukina, Plant and stress: course of lectures (Ekaterinburg, 2008) (in Russian)

5. E.V. Ionova, E.I. Nekrasova, Grain Econom. Rus. 5, 12-21 (2013) (in Russian)

6. O.V. Bychkova, E.A. Sharlaeva, Practical course in ecology. Evaluation of plants sustainability (Barnaul, Altai State University, 2015) (in Russian)

7. Yu.D. Akhlamov, Patent of Russian Federation 2477595 (2013) (in Russian). 